\title{
A Kinetic View on Proximity-dependent Selectivity of Carbon Dioxide Reduction on Bifunctional Catalysts
}

\author{
Huijun Jiang, Zhonghuai Hou*, and Yi Luo* \\ Hefei National Laboratory for Physical Sciences at the Microscale \& Department of Chemical Physics, iChEM, Uni- \\ versity of Science and Technology of China, Hefei, Anhui 230026, China.
}

\begin{abstract}
Multifunctional catalysts with distinct functional components are known to have much improved selectivity. However, the well-known proximity-dependent selectivity observed in several high profile experiments is yet to be understood. Here, we reveal that such dependence is closely associated with the kinetics involved. Based on reaction-diffusion dynamics together with a coarse-grained model, one famous example, namely the proximity-dependent selectivity from carbon dioxide to liquid fuels on a bifunctional catalyst composed of HZSM-5 and $\operatorname{In}_{2} \mathrm{O}_{3}$, has been systematically examined. It is found that the diffusion kinetics of the intermediate methanol generated on $\operatorname{In}_{2} \mathrm{O}_{3}$ plays a decisive role for the selectively. For different $\mathrm{In}_{2} \mathrm{O}_{3} / \mathrm{HZSM}-5$ proximities, the local methanol concentration induce a shift of the dominant process for subsequent methanol-to-hydrocarbon reactions inside HZSM-5, resulting in a preferred reaction window to generate favorable liquid fuels with profound high selectivity. Our findings emphasize the importance of the largely overlooked kinetic in the design of multifunctional catalysts.
\end{abstract}

Emissions of carbon oxide $\left(\mathrm{CO}_{2}\right)$ from burning of fossil fuels are now a global pressing environment issue due to the growing energy demand. As one of the solutions, chemical reduction provides a promising way to convert $\mathrm{CO}_{2}$ into value-added products ${ }^{1-8}$. So far, many monofunctional catalysts have been proposed to convert $\mathrm{CO}_{2}$ into various mono-carbon feedstocks such as carbon monoxide, formic acid, methane or methanol ${ }^{6-12}$. Nevertheless, the extremely low rate for the direct formation of $\mathrm{C}-\mathrm{C}$ bonds hinders the reduction of $\mathrm{CO}_{2}$ into hydrocarbons with multiple carbons on monofunctional catalysts ${ }^{13-17}$. As an alternate, bifunctional catalysts composed of two distinct functional components may bring new reactivity and/or selectivity to the $\mathrm{CO}_{2}$ reduction reaction $\left(\mathrm{CO}_{2} \mathrm{RR}\right)^{18-21}$. Very recently, a bifunctional catalyst composed of $\mathrm{H}$-form Zeolite Socony Mobil-5 (HZSM-5) and reducible indium oxides $\left(\operatorname{In}_{2} \mathrm{O}_{3}\right)$ was found to be of excellent performance to directly convert $\mathrm{CO}_{2}$ into liquid fuels with high selectivity ${ }^{18}$. It was found that, the reactant $\mathrm{CO}_{2}$ is hydrogenated on $\operatorname{In}_{2} \mathrm{O}_{3}$ to be the intermediate species, methanol $\left(\mathrm{CH}_{3} \mathrm{OH}\right)$, which is then transformed into hydrocarbons via methanol-to-hydrocarbon (MTH) reactions inside HZSM-5. Quite interestingly, the authors observed that the selectivity of liquid fuels depends strongly on the proximity between the two components, i.e., high selectivity lies in a moderate range of proximity below or above which $\mathrm{CO}_{2}$ is mainly reduced into methane. A similar phenomenon was also observed in the experiment of hydrocracking of hydrocarbons on a bifunctional catalyst comprising a mixture of zeolite $\mathrm{Y}$ and alumina binder with platinum metal deposited on either the zeolite or the binder, where the closest proximity of bifunctional active sites was found to be detrimental to the hydrocracking selectivity ${ }^{22}$. It thus indicates that the conventional 'the closer the better ${ }^{23-25}$ rule fails to correctly interpret the effect of the proximity between components of bifunctional catalysts. Apparently, a general mechanistic understanding for the proximity-induced optimal selectivity holds the key for the future development of multifunctional catalysts with controllable organization of catalytic components for new functional purposes.

Herein, we address such a mechanistic issue by proposing a theoretical framework for $\mathrm{CO}_{2} \mathrm{RR}$ on the $\mathrm{In}_{2} \mathrm{O}_{3} / \mathrm{HZSM}-5$ bifunctional catalyst. At the intercomponent level, we show that the local concentration of $\mathrm{CH}_{3} \mathrm{OH}$ for subsequent reactions inside HZSM-5 decreases sharply as $\mathrm{In}_{2} \mathrm{O}_{3} / \mathrm{HZSM}-5$ proximity increases. At the inner- HZSM-5 level, a reaction window for high selectivity of liquid fuels is uncovered as a result of the $\mathrm{CH}_{3} \mathrm{OH}$ concentration-induced shift of dominant reaction process by establishing a full kinetic model for MTH. The proximity-dependent selectivity is thus actually kineticcontrolled for $\mathrm{CO}_{2} \mathrm{RR}$ on the $\mathrm{In}_{2} \mathrm{O}_{3} / \mathrm{HZSM}_{-} 5$ bifunctional catalyst. Since the local concentration of the intermediate species is determined by the reaction-diffusion dynamics in between the two components of the bifunctional catalyst, the kinetic-controlled mechanism we revealed provides a powerful tool and opens a great opportunity for future design of bifunctional catalysts with special selectivity.

Proximity-dependent concentration of intermediate species for bifunctional catalysts. Generally, for bifunctional catalysts of two components A/B with distinct functional, the reactant $R$ fed in is catalyzed to be an intermediate 
species $S$ on component A, then $S$ diffuses onto component $\mathbf{B}$ and transforms into the product $P$ (Fig.1). Notice that, the intermediate species $S$ can only emerge at the

(a)
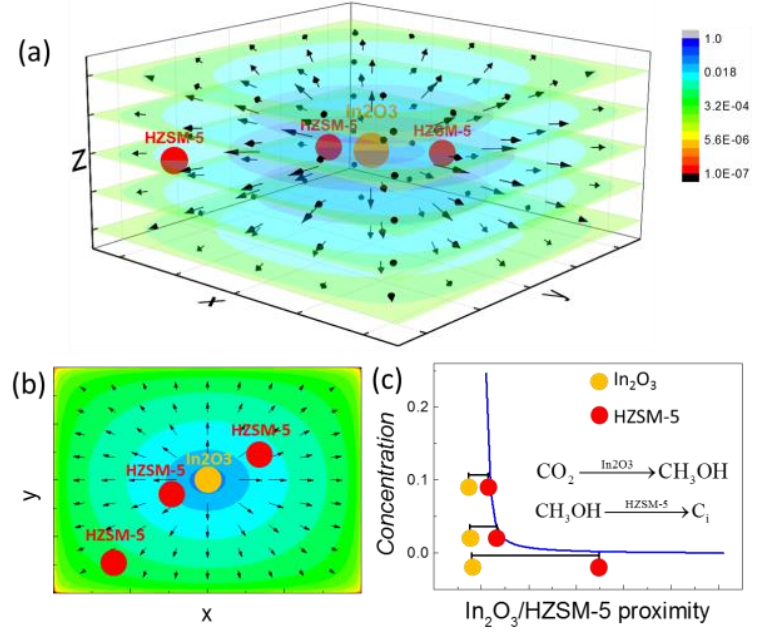

Figure 1. Proximity-dependent concentration of intermediate species on bifunctional catalysts of two components $\mathbf{A} / \mathbf{B}$ with distinct functional. Reactant $R$ fed in is catalyzed on component $\mathbf{A}$ to be intermediate species $S$ which is further catalyzed to be $P$ by component $\mathbf{B}$. Color map shows the concentration profile of $S$ in the neighborhood of component B in (a) 3-dimensional space and (b) a $2 \mathrm{D}$ cross-section over the component $\mathbf{A}$, where arrows indicate the concentration gradient. (c) Concentration of $S$ as a function of $\mathbf{A} / \mathbf{B}$ proximity.

position of component A. Due to the diffusion in space, amount of $S$ reaching the position of component B should decrease as the $\mathbf{A} / \mathbf{B}$ proximity increases. To illustrate clearly the spatial distribution of the intermediate species $S$, a calculation of the reaction-diffusion dynamics containing the production of $S$ at component A with a rate $v_{\mathrm{o}}$ and diffusion across its neighborhood with a diffusion constant $D_{\mathrm{o}}$ is performed (see details in the supplemental information, SI). The obtained 3-dimensional distribution (for $v_{0}=10^{3}$ and $D_{0}=0.1$ ) and its 2-dimensional cross-section are plotted in Fig. 1a and $1 \mathrm{~b}$, respectively. As expected, concentration of $S$ (the color map) fades quickly away from component $\mathbf{A}$ (the orange ball), which brings a concentration gradient (black arrows) pointing outwards. For component $\mathbf{B}$ located at different positions in the concentration field (such as red balls), the local concentration of $S$ for subsequent reactions on component $\mathbf{B}$ decreases sharply as $\mathbf{A} / \mathbf{B}$ distance increases (Fig.1c). We emphasize that Fig.1 provides a mean-field picture for the relation between $\mathbf{A} / \mathbf{B}$ proximity and local concentration of the intermediate species near $\mathbf{B}$. In other words, the averaged local concentration of $\mathrm{S}$ should decreases as the mean proximity decreases. In real systems, there are also other factors affect the diffusion kinetics of the intermediate species, for example, the space distribution of $\mathbf{A}$ and $\mathbf{B}$. The detailed arrangement of catalyst components may provide a practical way to tune the diffusion kinetics in experiments.

Kinetic modeling for hydrocarbon selectivity on HZSM-5. For $\mathrm{CO}_{2} \mathrm{RR}$ on $\mathrm{In}_{2} \mathrm{O}_{3} / \mathrm{HZSM}-5$ bifunctional catalyst, $\mathrm{In}_{2} \mathrm{O}_{3}$ provides the intermediate species $\mathrm{CH}_{3} \mathrm{OH}$, and hydrocarbons $\left(C_{i}, i=1,2,3, \ldots\right)$ are produced inside HZSM- $5^{18}$. To explore the effect of proximity between the two components on the hydrocarbon selectivity, we establish a coarsegrained model containing fully kinetics for MTH reactions inside HZSM- 5 where the influence of $\mathrm{In}_{2} \mathrm{O}_{3} / \mathrm{HZSM}$ 5 proximity is compacted into an efficient $\mathrm{CH}_{3} \mathrm{OH}$ local concentration near HZSM-5 component. As shown in Fig.2a, HZSM-5 is an aluminosilicate zeolite with 10membered oxygen ring and two types of channel systems. The straight $(5.3 \times 5.6 \AA)$ and sinusoidal $(5.1 \times 5.5 \AA)$ channels are perpendicular to each other and generate intersections (cages with diameters $8.9 \AA$ ). In our model, cages

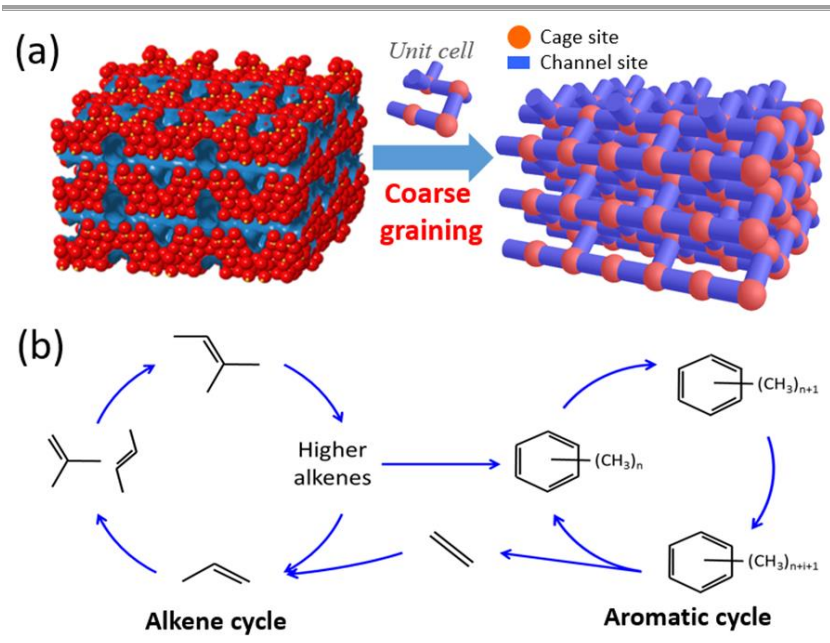

Figure 2. Kinetic modeling of methanol-to-hydrocarbon reaction on HZSM-5 zeolite. (a) Coarse-grained lattice for catalytic kinetics where cages and channel segments between two adjacent cages are coarse-grained to be cage sites and channel sites for kinetics. (b) The "dual-cycle" hydrocarbon pool mechanism to produce hydrocarbons with multiple carbons.

and channel segments between two adjacent cages are coarse-grained to be cage sites and channel sites for kinetics. The kinetic process includes adsorption and desorption of $\mathrm{CH}_{3} \mathrm{OH}$ at HZSM- 5 surface, desorption of subsequence products at the surface, diffusion of species from cage(channel) sites to channel(cage) sites, and reactions in each site. As it is still a great challenge to determine the exact elementary reactions, both experimentally and theoretically, here we also coarse-grain the reactions to be several apparent reactions. In steady state, main reactions to produce hydrocarbons of multiple carbons concern the well-known "dual-cycle" hydrocarbon pool (HCP) mechanism with two catalytic cycles at work ${ }^{26-31}$ (Fig.2b). For HZSM-5, the alkene-cycle preferring the channel sites involves growth and cracking of $\mathrm{C}_{3+}$, while 
the aromatic cycle tending to occur on the cage sites involves aromatic methylation and dealkylation to form polymethylbenzenes $\left(\mathrm{M}_{\mathrm{i}} \mathrm{B}, \mathrm{i}=\mathbf{0 , 1 , 2 \ldots}\right)$ and side chain growth of $\mathrm{M}_{\mathrm{i}} \mathrm{B}$ to produce $\mathrm{C}_{2}{ }^{32-34}$. The two cycles are connected by cyclization of long-chain hydrocarbons and $\mathrm{C}_{2}$ producing via HCP. Besides, MTH also includes the activation and deactivation of the active state for HCP mechanism. The activation concerns about the direct formation of $\mathrm{C}_{2}$ from $\mathrm{CH}_{3} \mathrm{OH}$ (the direct way), which is extremely slower than the indirect way via $\mathrm{HCP}^{13^{-17}, 3^{2}}$. It has also been revealed that the activity of the aromatic pool species decreases with an increasing number of methyl groups on the polymethylbenzene intermediates ${ }^{32,35}$. At last, $\mathrm{CH}_{3} \mathrm{OH}$ can also be catalyzed directly to $\mathrm{C}_{1}{ }^{36}$. More details about the kinetic model can be found in SI.

Standard "event-list" algorithm of kinetic Monte Carlo simulation $^{37}$ is applied to calculate the kinetics inside HZSM-5. Involved chemical events are listed in Supplementary Table 1.

(a)
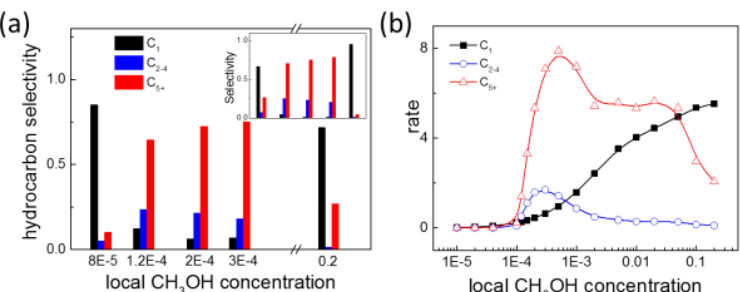

(c)

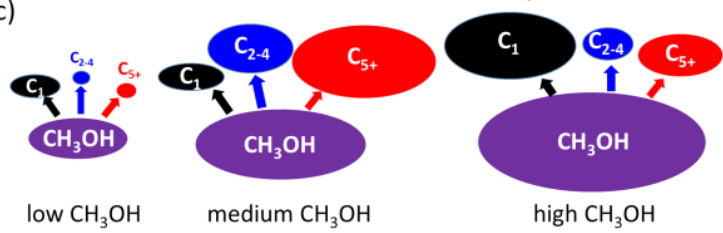

Figure 3. Local methanol concentration induced optimal $\mathrm{C}_{5+}$ selectivity. (a) Selectivity and (b) producing rate of hydrocarbons as functions of local $\mathrm{CH}_{3} \mathrm{OH}$ concentration. (c) Schematic of the local-concentration-dependent hydrocarbon producing rates. Inset in (a) is experimental data from Ref. 18.

Kinetic-controlled hydrocarbon selectivity. Based on the proposed kinetic model, the experimentally revealed dependence of liquid fuels $\left(\mathrm{C}_{5+}\right)$ selectivity on the proximity (inset in Fig.3a) is well reproduced with parameters in Supplementary Table 2. As shown in Fig.3a, the main product is $\mathrm{C}_{1}$ for low and high local $\mathrm{CH}_{3} \mathrm{OH}$ concentration $c_{m}$ and turns to be $\mathrm{C}_{5^{+}}$for medium $c_{m}$, corresponding to the experimental observation that high selectivity of $\mathrm{C}_{5^{+}}$ lies in a moderate range of proximity ${ }^{18}$. Additionally, it is noted that $C_{1}$ selectivity in our simulation results for large $c_{m}$ is smaller than the experimental one in Ref.18, the reason may be that $\mathrm{C}_{1}$ can also be produced on $\operatorname{In}_{2} \mathrm{O}_{3}$ by reverse water gas shift reactions. Besides of the hydrocarbon selectivity, we are also interested in how the producing rates of hydrocarbons depend on $c_{m}$. As shown in Fig.3b, the rate for $C_{1}$ increases monotonically with in- creasing $c_{m}$. For $\mathrm{C}_{2-4}$ and $\mathrm{C}_{5^{+}}$, the rates increase sharply as $c_{m}$ increases from a very low value to a moderate range, indicating that these hydrocarbons are generated by a self-catalytic process, i.e., the alkene and aromatic cycles for HCP. For high $c_{m}$, producing rates of $\mathrm{C}_{2-4}$ and $\mathrm{C}_{5^{+}}$drop to be very slow again. Such a turnover of $\mathrm{C}_{5+}$ producing rate can be illustrated clearly by the schematic in Fig.3c, where spheres colored in purple denote the local $\mathrm{CH}_{3} \mathrm{OH}$ concentration, and ones in black, blue and red are the producing rates for $\mathrm{C}_{1}, \mathrm{C}_{2-4}$ and $\mathrm{C}_{5+}$, respectively. This observation indicates that the local-concentration-induced turnover of $\mathrm{C}_{5^{+}}$selectivity should be attributed directly to the kinetic events concerning about $\mathrm{C}_{2+}$, while the production of $C_{1}$ affects the $C_{5+}$ selectivity only by providing a parallel reaction.

To reveal the mechanism underlying the localconcentration-induced turnover of $\mathrm{C}_{5^{+}}$selectivity, the probabilities of events for $C_{1}$ producing (black area in Fig.4a), $C_{2}$ producing via the direct way (blue area in Fig.4a) and that via HCP (red area in Fig.4a), are obtained by a detailed analysis of the kinetic trajectories in steady states. For low local $\mathrm{CH}_{3} \mathrm{OH}$ concentration such as $c_{m}<0.008, C_{2}$, the initial species for HCP, is mainly generated via the direct way. Since the direct formation of $C_{2}$ is extremely slow, $C_{1}$ producing event is then of course the dominant one. For $c_{m}$ slightly larger than o.oo8, producing event of $\mathrm{C}_{2}$ via $\mathrm{HCP}$ changes to be the dominant one, resulting from the fact that $\mathrm{HCP}$ is a self-catalytic process whose rate should increase much faster than producing event of $\mathrm{C}_{1}$ as local $\mathrm{CH}_{3} \mathrm{OH}$ concentration increases. Notice that, $C_{2}$ is formed exclusively from the lower polymethylbenzenes in cage sites during the aromatic cycle in $\mathrm{HCP}^{32}$. Nevertheless, the lower polymethylbenzenes may be further methylated to be higher polymethylbenzenes which occupy the catalytic sites to deactivate HCP. In the model, the deactivating species are considered to be pentamethylbenzene $\left(\mathrm{M}_{5} \mathrm{~B}\right)$ and hexamethylbenzene $\left(\mathrm{M}_{6} \mathrm{~B}\right)$ for MTH in HZSM-5. The percentage of deactivated cage sites occupied fully by $\mathrm{M}_{5-6} \mathrm{~B}$ as a function of the local $\mathrm{CH}_{3} \mathrm{OH}$ concentration is also plotted in Fig.4a (the green line). It is observed that, there are no deactivated cage sites when $C_{1}$ production is the dominant event at low $c_{m}$. As the HCP changes to be dominant, deactivated cage sites emerge and their percentage increases as $c_{m}$ increases, leading to the drop of $C_{2}$ producing event via HCP. For large enough $c_{m}$, almost all of cage sites are deactivated, thus, reaction deactivation dominants. The parameter range in between the $C_{1}$ dominant state and the deactivation dominant state provides a reaction window for experimentally observed proximityinduced high $\mathrm{C}_{5^{+}}$selectivity. To illustrate clearly the localconcentration-induced shift of the dominant process, the whole reaction network is presented in Fig.4b. Firstly, $\mathrm{CH}_{3} \mathrm{OH}$ transforms directly to be $\mathrm{C}_{1}$ or $\mathrm{C}_{2}$. $\mathrm{C}_{2}$ then starts the self-catalytic HCP with the alkene cycle and aromatic cycle. Finally, lower polymethylbenzenes which are active species in the aromatic cycle are methylated to be higher 
polymethylbenzenes deactivating the $\mathrm{HCP}$ in return. The higher the local $\mathrm{CH}_{3} \mathrm{OH}$ concentration is, the deeper the reaction network goes. As the local concentration is determined by diffusion process between the two components of the bifunctional catalyst, the high selectivity lying in a moderate range of proximity is actually a kineticcontrolled hydrocarbon selectivity.
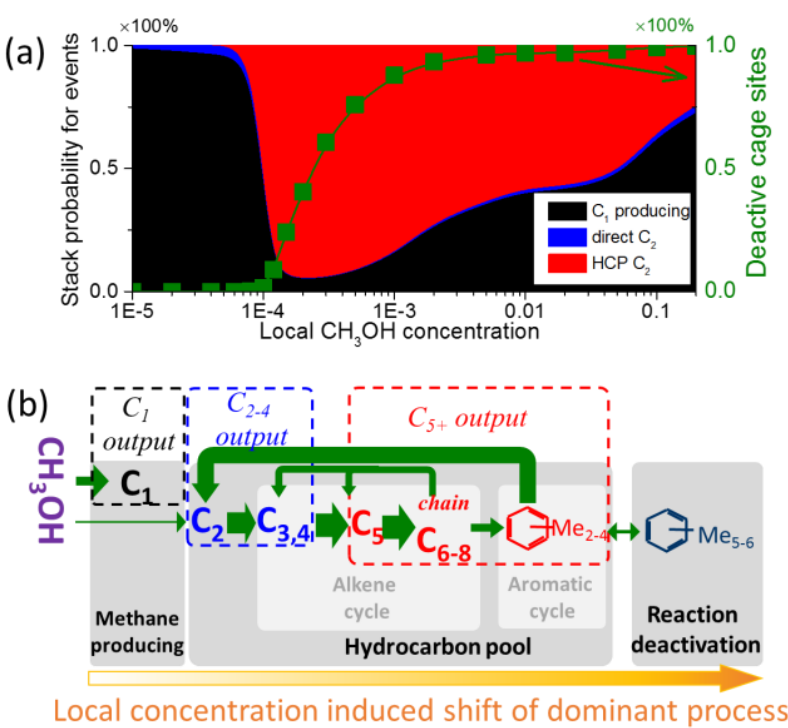

Figure 4. Mechanism of kinetic-controlled selectivity for methanol-to-hydrocarbon on HZSM-5 zeolites. (a) Stack probability of events for $C_{1}$ producing, $C_{2}$ producing via the direct $\mathrm{C}-\mathrm{C}$ formation (direct $\mathrm{C}_{2}$ ) and via the hydrocarbon pool $\left(\mathrm{HCP} \mathrm{C}_{2}\right)$, normalized by the total number of the three events. The green line with scatters is the percentage of deactivate cage sites. (b) Schematic of the reaction network and the local-concentration-induced shift of the dominant process, i.e., the dominant process is the producing of $C_{1}$, the $\mathrm{HCP}$ or the deactivation as local concentration increases. Width of green arrows indicates qualitatively the relative rate constant for corresponding events.

Possible ways to tune the reaction window for high $C_{5^{+}}$selectivity. As the diffusion of the intermediate species is a key factor for the proximity-dependent selectivity of $\mathrm{C}_{5+}$ on $\mathrm{In}_{2} \mathrm{O}_{3} / \mathrm{HZSM}-5$ bifunctional catalyst, it is expected that the reaction window for high selectivity should be tunable by kinetic parameters concerning the diffusion process. The shortest proximity $l_{\mathrm{o}}$ for the onset of the reaction window and the window size $\Delta l$ as functions of the diffusion constant $D_{0}$ in between $\operatorname{In}_{2} \mathrm{O}_{3}$ and HZSM- 5 and the $\mathrm{CH}_{3} \mathrm{OH}$ producing rate $v_{\mathrm{o}}$ on $\mathrm{In}_{2} \mathrm{O}_{3}$ are plotted in Fig.5. As $D_{\mathrm{o}}$ increases, the shortest onset proximity $l_{0}$ decreases monotonically. Quite interestingly, it is observed that the size of the reaction window firstly increases to a maximal value and then decreases, presenting an optimal size for the reaction window of high $\mathrm{C}_{5^{+}}$selectivity (Fig.5a). Such an optimal size can also be found as the $\mathrm{CH}_{3} \mathrm{OH}$ producing rate $v_{\mathrm{o}}$ increases, while the shortest onset proximity $l_{\mathrm{o}}$ monotonically increases. Besides, the detailed arrangement of the two components can also affect the reaction window, which may provide new routines for tunable selectivity of bifunctional catalysts and deserve further systematic investigation in future.
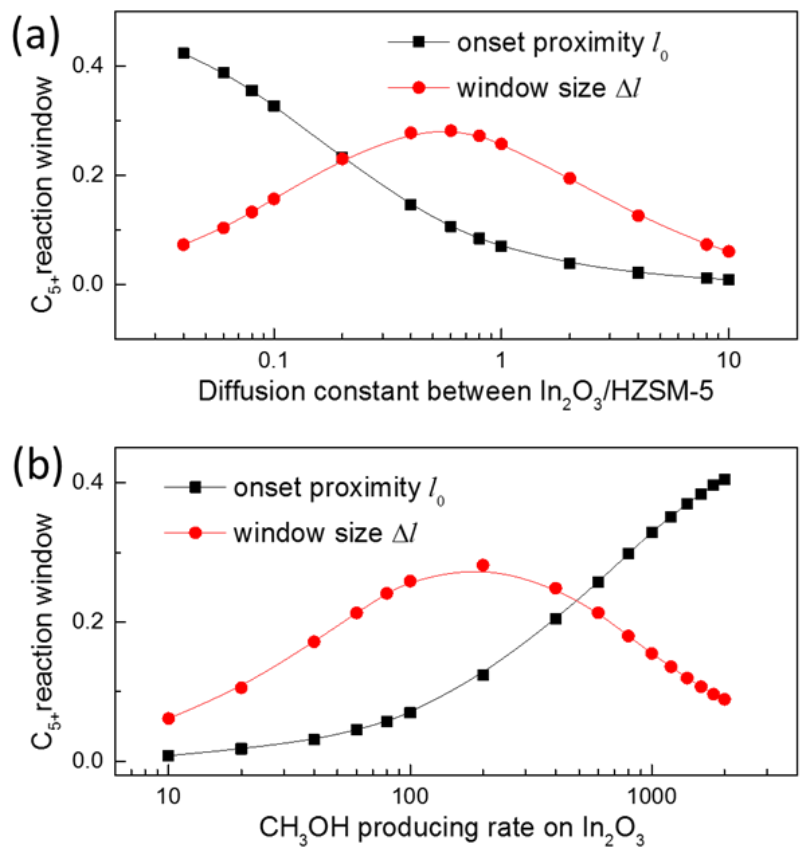

Figure 5. Effect of the inter-component kinetics on the reaction window for high $\mathrm{C}_{5+}$ selectivity. The dependence of the shortest proximity $l_{0}$ for the onset of the reaction window and the window size $\Delta l$ on (a) diffusion constant of $\mathrm{CH}_{3} \mathrm{OH}$ between $\mathrm{In}_{2} \mathrm{O}_{3} / \mathrm{HZSM}_{-} 5$ and (b) $\mathrm{CH}_{3} \mathrm{OH}$ producing rate on $\mathrm{In}_{2} \mathrm{O}_{3}$.

In summary, we revealed that the proximity-dependent selectivity of liquid fuel $\left(\mathrm{C}_{5+}\right)$ from $\mathrm{CO}_{2} \mathrm{RR}$ is actually kinetic-controlled on the $\mathrm{In}_{2} \mathrm{O}_{3} / \mathrm{HZSM}-5$ bifunctional catalyst where $\mathrm{CO}_{2}$ is catalyzed to be the intermediate species $\mathrm{CH}_{3} \mathrm{OH}$ on component $\mathrm{In}_{2} \mathrm{O}_{3}$ and hydrocarbons are formed via MTH reactions inside component HZSM-5. A moderate local concentration of $\mathrm{CH}_{3} \mathrm{OH}$ was found to be the key factor for the reaction window of high $\mathrm{C}_{5^{+}}$hydrocarbons selectivity, while the local concentration depends strongly on and can be tuned by the diffusion of $\mathrm{CH}_{3} \mathrm{OH}$ from $\mathrm{In}_{2} \mathrm{O}_{3}$ to $\mathrm{HZSM}-5$. Our finding emphasizes that, along with the energetic, the kinetic is also an important factor in the design of bifunctional catalysts. Since the diffusion of the intermediate species between components is determined by the producing rate, diffusion constant, boundary conditions, the arrangement of catalyst components, etc, the kinetic-controlled selectivity provides many routines for tunable selectivity of bifunctional catalysts, and may inspire a new area for future design of multifunctional catalysts with special selectivity.

\section{ASSOCIATED CONTENT}


Supporting Information. The Supporting Information is available.

Supplementary Notes of simulation details of the intermediate species distribution for A/B bifunctional catalysts; kinetic modeling details for hydrocarbon selectivity on HZSM-5; Determination of parameters for the kinetic model; figure for dependence of the diffusion constant on the number of carbon atoms for alkanes; tables for chemical events and kinetic parameters for simulation of kinetics in $\mathrm{HZSM}_{-5}$ (PDF).

\section{AUTHOR INFORMATION}

\section{Corresponding Author \\ *hzhlj@ustc.edu.cn \\ *yiluo@ustc.edu.cn \\ ORCID}

Hui-Jun Jiang: oooo-ooo1-7243-5431

Zhong-Huai Hou: oooo-0oo3-1241-7041

Yi Luo: 0000-0003-0007-0394

\section{Author Contributions}

H.-J.J., Z.-H.H., and Y.L. conceived the idea and co-wrote the paper. Z.-H.H., and Y.L. supervised the project. H.-J.J. established the kinetic model and performed the theoretical simulations. All the authors discussed the results and commented on the manuscript.

\section{Notes}

The authors declare no competing financial interest.

\section{ACKNOWLEDGMENT}

This work is supported by MOST (2016YFAo400904, 2017YFA0303500, 2018YFAo208702), by NSFC (21973085, 21833007, 21790350, 21673212, 21521001, 21473165, 21403204, 21421063, 21633007), and by Anhui Initiative in Quantum Information Technologies (AHYogoooo).

\section{REFERENCES}

(1) Aresta, M.; Dibenedetto, A.; Angelini, A., Catalysis for the Valorization of Exhaust Carbon: from $\mathrm{CO}_{2}$ to Chemicals, Materials, and Fuels Technological Use of $\mathrm{CO}_{2}$. Chem. Rev. 2014, 114, 1709-1742.

(2) Qiao, J.; Liu, Y.; Hong, F.; Zhang, J., A Review of Catalysts for the Electroreduction of Carbon Dioxide to Produce Lowcarbon Fuels. Chem. Soc. Rev. 2014, 43, 631-675.

(3) Appel, A. M.; Bercaw, J. E.; Bocarsly, A. B.; Dobbek, H.; DuBois, D. L.; Dupuis, M.; et al., Frontiers, Opportunities, and Challenges in Biochemical and Chemical Catalysis of $\mathrm{CO}_{2}$ Fixation. Chem. Rev. 2013, 113, 6621-6658.

(4) Lin, S.; Diercks, C. S.; Zhang, Y.-B.; Kornienko, N.; Nichols, E. M.; Zhao, Y.; et al., Covalent Organic Frameworks Comprising Cobalt Porphyrins for Catalytic $\mathrm{CO}_{2}$ Reduction in Water. Science 2015, 349, 1208-1213.

(5) Lu, Q.; Rosen. J.; Zhou, Y.; Hutchings, G. S.; Kimmel, Y. C.; Chen, J. G.; et al., A Selective and Efficient Electrocatalyst for Carbon Dioxide Reduction. Nat. Commun. 2014, 5, 3242.
(6) Gao, S.; Lin, Y.; Jiao, X.; Sun, Y.; Luo, Q.; Zhang, W.; et al., Partially Oxidized Atomic Cobalt Layers for Carbon Dioxide Electroreduction to Liquid Fuel. Nature 2016, 529, 68-71.

(7) Costentin, C.; Drouet, S.; Robert, M.; Saveant, J.-M.;. A Local Proton Source Enhances $\mathrm{CO}_{2}$ Electroreduction to $\mathrm{CO}$ by a Molecular Fe Catalyst. Science 2012, 338, 90-94.

(8) Rosen, B. A.; Salehi-Khojin, A.; Thorson, M. R.; Zhu, W.; Whipple, D. T.; Kenis, P. J. A.; et al., Ionic Liquid-mediated Selective Conversion of $\mathrm{CO}_{2}$ to $\mathrm{CO}$ at Low Overpotentials. Science 2011, 334, 643-644.

(9) Zhang, S.; Kang, P.; Meyer, T. J., Nanostructured Tin Catalysts for Selective Electrochemical Reduction of Carbon Dioxide to Formate. J. Am. Chem. Soc. 2014, 136, 1734-1737.

(10) Graciani, J.; Mudiyanselage, K.; Xu, F.; Baber, A. E.; Evans, J.; Senanayake, S. D.; et al., Highly Active Copper-ceria and Copper-ceria-titania Catalysts for Methanol Synthesis from CO2. Science 2014, 345, 546-550.

(11) Moret, S.; Dyson, P. J.; Laurenczy, G., Direct Synthesis of Formic Acid from Carbon Dioxide by Hydrogenation in Acidic Media. Nat. Commun. 2014, 5, 4017.

(12) Liu, M.; Pang, Y.; Zhang, B.; De Luna, P.; Voznyy, O.; Xu, J.; et al., Enhanced Electrocatalytic $\mathrm{CO}_{2}$ Reduction via Fieldinduced Reagent Concentration. Nature 2016, 537, 382-386.

(13) Sakakura, T.; Choi, J.-C.; Yasuda, H., Transformation of Carbon Dioxide. Chem. Rev. 2007, 107, 2365-2387.

(14) Montoya, J. H.; Peterson, A. A.; Nørskov, J. K., Insights into $\mathrm{CC}$ Coupling in $\mathrm{CO}_{2}$ Electroreduction on Copper Electrodes. ChemCatChem 2013, 5, 737-742.

(15) Lesthaeghe, D.; van Speybroeck, V.; Marin, G. B.; Waroquier, M., Understanding the Failure of Direct CC Coupling in the Zeolite - Catalyzed Methanol - to - Olefin Process. Angew. Chem. Int. Ed. 2006, 118, 1746-1751.

(16) Lesthaeghe, D.; van Speybroeck, V.; Marin, G. B.; Waroquier, M., The Rise and Fall of Direct Mechanisms in Methanol-to-olefin Catalysis: An Overview of Theoretical Contributions. Ind. Eng. Chem. Res. 2007, 46, 8832-8838.

(17) Lesthaeghe, D.; van Speybroeck, V.; Marin, G. B.; Waroquier, M., What Role do Oxonium Ions and Oxonium Ylides Play in the ZSM-5 Catalysed Methanol-to-olefin Process? Chem. Phys. Lett. 2oo6, 417, 309-315.

(18) Gao, P.; Li, S.; Bu, X.; Dang, S.; Liu, Z.; Wang, H.; et al., Direct Conversion of $\mathrm{CO}_{2}$ into Liquid Fuels with High Selectivity over a Bifunctional Catalyst. Nat. Chem. 2017, 9, 1019-1024.

(19) Liu, X.; Wang, M.; Zhou, C.; Zhou, W.; Cheng, K.; Kang, J.; et al., Selective Transformation of Carbon Dioxide into Lower Olefins with a Bifunctional Catalyst Composed of $\mathrm{ZnGa}_{2} \mathrm{O}_{4}$ and SAPO-34. Chem. Commun. 2018, 54, 140-143.

(20) Ni, Y.; Chen, Z.; Fu, Y.; Liu, Y.; Zhu, W.; Liu, Z., Selective Conversion of $\mathrm{CO}_{2}$ and $\mathrm{H}_{2}$ into Aromatics. Nat. Commun 2018, 9, 3457.

(21) Wei, J.; Yao, R.; Ge, Q.; Wen, Z.; Ji, X.; Fang, C.; et al., Catalytic Hydrogenation of $\mathrm{CO}_{2}$ to Isoparaffins over $\mathrm{Fe}$ based Multifunctional Catalysts. ACS Catal. 2018, 8, 99589967.

(22) Zecevic, J.; Vanbutsele, G.; de Jong, K. P.; Martens, J. A., Nanoscale Intimacy in Bifunctional Catalysts for Selective Conversion of Hydrocarbons. Nature 2015, 528, 245-248.

(23) Weisz, P. B., Polyfunctional Heterogeneous Catalysis. Adv. Catal. 1962, 13, 137-190. 
(24) Francis, J.; Guillon, E.; Bats, N.; Pichon, C.; Corma, A.; Simon, L., Design of Improved Hydrocracking Catalysts by Increasing the Proximity Between Acid and Metallic Sites. Appl. Catal. A 2011, 409, 140-147.

(25) Kim, J.; Kim, W.; Seo, Y.; Kim J.-C. .; Ryoo, R., n-Heptane Hydroisomerization over Pt/MFI Zeolite Nanosheets: Effects of Zeolite Crystal Thickness and Platinum Location. J. Catal. 2013, 301, 187-197.

(26) Erichsen, M. W.; Svelle, S.; Olsbye, U., The Influence of Catalyst Acid Strength on the Methanol to Hydrocarbons (MTH) Reaction. Catal. Today 2013, 215, 216-223.

(27) Olsbye, U.; Svelle, S.; Bjorgen, M.; Beato, P.; Janssens, T. V.; Joensen, F.; et al., Conversion of Methanol to Hydrocarbons: How Zeolite Cavity and Pore Size Controls Product Selectivity. Angew. Chem. Int. Ed. 2012, 51, 5810-5831.

(28) Dahl, I. M.; Kolboe, S., On the Reaction Mechanism for Propene Formation in the MTO Reaction over SAPO-34. Catal. Lett. 1993, 20, 329-336.

(29) Dahl, I. M.; Kolboe, S., On the Reaction Mechanism for Hydrocarbon Formation from Methanol over SAPO-34: I. Isotopic Labeling Studies of the Co-reaction of Ethene and Methanol. J. Catal. 1994, 149, 458-464.

(30) Dahl, I. M.; Kolboe, S., On the Reaction Mechanism for Hydrocarbon Formation from Methanol over SAPO-34: 2. Isotopic Labeling Studies of the Co-reaction of Propene and Methanol. J. Catal. 1996, 161, 304-309.

(31) Lesthaeghe, D.; van der Mynsbrugge, J.; Vandichel, M.; Waroquier, M.; van Speybroeck, V., Full Theoretical Cycle for both Ethene and Propene Formation during Methanol-toOlefin Conversion in H-ZSM-5. ChemCatChem 2011, 3, 208212.

(32) Svelle, S.; Joensen, F.; Nerlov, J.; Olsbye, U.; Lillerud, K. P.; Kolboe, S.; et al., Conversion of Methanol into Hydrocarbons over Zeolite H-ZSM-5: Ethene Formation Is Mechanistically Separated from the Formation of Higher Alkenes. J. Am. Chem. Soc. 20o6, 128, 14770-14771.

(33) Bjørgen, M.; Svelle, S.; Joensen, F.; Nerlov, J.; Kolboe, S.; Bonino, F.; et al., Conversion of Methanol to Hydrocarbons over Zeolite H-ZSM-5: On the Origin of the Olefinic Species. J. Catal. 2007, 249, 195-207.

(34) Liang, T.; Chen, J.; Qin, Z.; Li, J.; Wang, P.; Wang, S.; et al., Conversion of Methanol to Olefins over H-ZSM-5 Zeolite: Reaction Pathway Is Related to the Framework Aluminum Siting. ACS Catal. 2016, 6, 7211-7325.

(35) Bjørgen, M.; Joensen, F.; Lillerud, K. P.; Olsbye, U.; Svelle, S., The Mechanisms of Ethene and Propene Formation from Methanol over High Silica H-ZSM-5 and H-beta. Catal. Today 2009, 142, 90-97.

(36) Kaarsholm, M.; Joensen, F.; Nerlov, J.; Cenni, R.; Chaouki, J.; Patience, G. S., Phosphorous Modified ZSM-5: Deactivation and Product Distribution for MTO. Chem. Eng. Sci. 2007, 62, 5527-5532.

(37) Gillespie, D. T., Stochastic Simulation of Chemical Kinetics. Annu. Rev. Phys. Chem. 2007, 58, 35-55. 